\title{
Delphi method and nominal group technique in family planning and reproductive health research
}

\author{
Edwin van Teijlingen, Emma Pitchforth, Caroline Bishop, Elizabeth Russell
}

\section{Introduction}

Both the Delphi method and nominal group technique offer structured, transparent and replicable ways of synthesising individual judgements ${ }^{1}$ and have been used extensively for priority setting and guideline development in health-related research including reproductive health. ${ }^{2-4}$ Within evidence-based practice they provide a means of collating expert opinion where little evidence exists. ${ }^{1}$ They are distinct from many other methods because they incorporate both qualitative and quantitative approaches. Both methods are inherently flexible; this article also discusses other strengths and weaknesses of these methods.

\section{Consensus methods}

Delphi methods and the nominal group technique are two of the most common, so-called 'consensus methods' commonly used to synthesise information from conflicting evidence. Consensus methods are primarily concerned with deriving quantitative estimates through qualitative approaches. This means a greater flexibility as it allows for a wider range of study types to be considered than is usual in statistical reviews (Box 1). Delphi methods concentrate on measuring consensus whereas the nominal group technique can be used to develop consensus but without the limitations of more informal methods of reaching consensus such as committees, which are prone to domination by powerful individuals and influenced by personalities. 5 A recent example of the use of the nominal group technique for consensus development was the adaptation of the World Health Organization's Selected Practice Recommendations for Contraceptive Use for use in the UK. ${ }^{2}$ This formed the basis of the Faculty of Family Planning and Reproductive Health Care's guidance for practice. 6

J Fam Plann Reprod Health Care 2006; 32(4): 249-252

(Accepted 15 August 2006)

Dugald Baird Centre for Research on Women's Health and Department of Public Health, Medical School, University of Aberdeen, Aberdeen, UK

Edwin van Teijlingen, MEd, PhD, Medical Sociologist/Reader in Public Health

\section{Department of Health Sciences, University of Leicester,} Leicester, UK

Emma Pitchforth, BSc, PhD, Lecturer in Social Science and Health

Islington NHS Primary Care Trust, London, UK

Caroline Bishop, BSc, MSc, Speech and Language Therapist

Department of Public Health, Medical School, University of Aberdeen, Aberdeen, UK

Elizabeth Russell, MD, FFCM, Professor Emerita

Correspondence to: Dr Edwin van Teijlingen, Department of Public Health and Dugald Baird Centre for Research on Women's Health, University of Aberdeen, Polwarth Building, Medical School, Foresterhill, Aberdeen AB25 2ZD, UK.

Tel: +44 1224 552495. Fax: +44 1224550529.

E-mail: van.teijlingen@abdn.ac.uk

\begin{tabular}{|c|c|}
\hline \multicolumn{2}{|c|}{ Box 1: Features of consensus methods ${ }^{a}$} \\
\hline Anonymity & $\begin{array}{l}\text { To avoid dominance; achieved by use of a } \\
\text { questionnaire in the Delphi method and private } \\
\text { ranking in the nominal group technique. }\end{array}$ \\
\hline Iteration & $\begin{array}{l}\text { Processes occur in 'rounds', allowing individuals to } \\
\text { change their opinions. }\end{array}$ \\
\hline $\begin{array}{l}\text { Controlled } \\
\text { feedback }\end{array}$ & $\begin{array}{l}\text { Showing the distribution of the group's response } \\
\text { (indicating to each individual their own previous } \\
\text { response in Delphi). }\end{array}$ \\
\hline $\begin{array}{l}\text { Statistical } \\
\text { group response }\end{array}$ & $\begin{array}{l}\text { Expressing judgment using summary measures of } \\
\text { the full group response giving more information } \\
\text { than just a consensus statement. }\end{array}$ \\
\hline
\end{tabular}

aAdapted from Jones and Hunter. ${ }^{17}$

\section{Delphi method}

The Delphi method aims to gather consensus of opinion, attitudes and choice about a topic from a selected panel without the need for people to meet. Although the Delphi method is often used with experts, it can also be used in eliciting patients' views. ${ }^{7}$

It is important to consider the Delphi method as a process involving several phases or stages rather than a single data collection event. Typically, questionnaires are posted to individual panel members; the questions are initially open-ended and seek individual responses. The open-ended responses are then analysed to generate a series of statements, which are compiled into another questionnaire and sent back to the individual participants who are asked to rank their agreement with each. This process (Figure 1) can be repeated several times and the rerankings analysed to ascertain the degree of consensus. ${ }^{8}$ After the second round, the rankings from different participants are summarised and included in a repeat version of the questionnaire. Participants can then see how others ranked items and decide whether they want to reconsider their own ranking. Delphi studies typically involve three rounds, 9,10 but the number needed will depend on the research question and time available. ${ }^{11}$ Involving more rounds may be beneficial in reaching consensus but is time consuming and difficult to maintain high response rates.

\section{Strengths of the Delphi method}

The main advantage of the Delphi method is that there is no need for participants (e.g. busy professionals or managers) to meet up ${ }^{12}$ and hence it is a relatively inexpensive method of gaining a large number of responses. It also allows the involvement of participants from disparate geographical areas and has been used in international health research. For example, Wang et al. involved nationally and internationally known reproductive health experts in their study to generate reproductive health indicators for China's rural areas. ${ }^{3}$ Participants are generally contacted by mail, but increasingly the Internet is used, which also facilitates international research. ${ }^{13}$ Also, as the participants are consulted on a number of occasions, they have the flexibility of changing their statements and suggestions or withdrawing some altogether as a period of 'considered thought' is allowed. The anonymity of the process means that more controversial issues can be raised. 
A further advantage of the Delphi method is that it overcomes the problem of a few individuals dominating discussions. 14

\section{Weaknesses of the Delphi method}

There has been little research in assessing the validity or reliability of the Delphi method. ${ }^{15}$ Some argue that consensus methods should not be viewed as scientific methods for creating new knowledge and, therefore, should not be judged using these criteria. ${ }^{5}$ One of the problems in using any criteria is that little detail is usually published about design, inclusion criteria, sampling or methods of analysis. ${ }^{16}$

This said, there are some limitations commonly associated with the Delphi method, primarily concerning poorly conducted studies rather than fundamental critiques. ${ }^{17}$ Many of these can be minimised if considered at the outset and by taking a rigorous approach. In evaluating the credibility or quality of a Delphi study it would be useful to examine whether the following issues have been considered. Although researchers can minimise the workload for the Delphi participants it is often a considerable amount of work, which is likely to affect the method's acceptability. Response rates can be low and often decrease as the rounds progress. ${ }^{18}$ Considerable effort may be needed beforehand to get professionals to 'buy in' to the process. Charlton et al. ${ }^{14}$ experienced nonresponse because it was decided, in order to minimise costs, that no initial meeting be held explaining the study to those targeted; this meant that there was a lack of knowledge about the objectives of the study and this in turn led to a large number of invitees not participating.

As the Delphi is a consensus method, it tries to obtain consensus and to 'centralise opinion' and important minority issues may be missed due to non-conformity of general opinion. ${ }^{19}$ Loss of objectivity and researcher bias in analysing findings and generating questions are also possible. ${ }^{10,18}$ In a study looking at general practitioners' information needs, Green et al. outlined the problems involved in refining earlier responses to move towards consensus. ${ }^{10}$ Whilst the researchers envisaged a respondent-led process in which verbatim responses were fed back, it became clear that participants needed help to be able to move on to their next assessment. For the third round they included only high-consensus statements and reduced the number of categories, in the process losing the minority views.

Sampling, as with any research method, is crucial, as the representativeness of the group is another potential weakness of the Delphi method. For example, asking too specific a group to participate could limit the scope of opinion and expertise; it might be more appropriate to involve a multidisciplinary team than a highly specialised team. ${ }^{7}$ A study conducted in Kenya identified potential representative Delphi panel members after "the project leader interviewed teachers in local schools and consulted members of the twelve communities in search of local individuals generally enjoying the trust of most villagers". 20 Campbell et al. concluded that both panel composition and types of feedback influenced the judgements made. ${ }^{21}$ Given that response rates for the Delphi method can be low, it may be pragmatic to select participants who have an interest and involvement in the question being explored; however, this should be balanced with seeking relative impartiality. 22

\section{Nominal group technique}

The nominal group technique is based on highly structured meetings to gather information from experts about a particular issue. ${ }^{17}$ It has been used as a means of prioritising health problems within communities and health indicators for use in reproductive and family planning research. $2,3,23$ This method was developed to avoid the problems of group interaction that may occur in focus groups. ${ }^{24}$ Different modifications have been made to the nominal group technique and it may be used solely as a ranking exercise 25 or with the aim of obtaining consensus. ${ }^{26}$ The group is highly controlled and discussion is restricted to the later stages of the group process, hence it is a group in name only, that is, nominally. 27

Although modifications are made to suit the purpose of the study, there are generally four or five stages involved in

Box 2: Stages of nominal group technique

STAGE 1: Formulation of the nominal group question.

STAGE 2: Group members independently and privately record ideas and opinions relating to the question or problem of interest.

STAGE 3: Ideas or rankings are recorded, often in a round-robin feedback session.

STAGE 4: Discussion to clarify and categorise different ideas to obtain a list of options.

STAGE 5: Group members independently rank the different options. The group decision is based on consensus achieved during this ranking process. 


\begin{tabular}{|c|c|c|}
\hline & Strengths & Limitations \\
\hline Delphi method & $\begin{array}{l}\text { - Overcomes some problems of group interaction } \\
\text { - Participants do not meet in one place } \\
\text { - Enclatively inexpensive } \\
\text { - Allows period of 'considered thought' } \\
\text { - Does not allow individuals to dominate }\end{array}$ & $\begin{array}{l}\text { Reaching consensus can be time consuming } \\
\text { - Difficult to maintain high response rate } \\
\text { - Researcher bias can be a problem }\end{array}$ \\
\hline $\begin{array}{l}\text { Nominal group } \\
\text { technique }\end{array}$ & $\begin{array}{l}\text { - Overcomes some problems of group interaction } \\
\text { - Allows period of 'considered thought' } \\
\text { - Encourages minority views to be aired } \\
\text { - Produces qualitative and quantitative data }\end{array}$ & $\begin{array}{l}\text { - Potential for false consensus } \\
\text { - Selection bias can be a problem } \\
\text { Needs experienced facilitator }\end{array}$ \\
\hline
\end{tabular}

the nominal group technique (Box 2). ${ }^{17}$ Unlike the Delphi method, participants attend structured meetings facilitated by a third-party moderator. After setting the key nominal group technique question, participants are typically asked to record ideas - independently and before meeting the group about the question of interest. These ideas are then shared one by one within the group and discussion ensues where clarification is required. The ideas are collated and summarised and each group member is asked to rank these. The combination of discussion and ranking allows qualitative and quantitative data to be gathered and analysed. In the second round, members receive the rankings, which are discussed and re-ranked. Moderators should refrain from adding their own opinion during the meeting.

Similar considerations concerning the facilitator and participant selection are required for the nominal group technique as for other consensus methods. ${ }^{21}$ The facilitator may be a topic expert or a non-expert who has credibility with the participants; ${ }^{26}$ either way they should be facilitating not leading or directing the group. It is important to select appropriate experts to participate in the nominal group technique as there is a high potential for selection bias and the mix of participants can have an effect on the final outcomes. ${ }^{17}$ However, with a growing emphasis on the importance of health services users' views ('consumers') in health policy making, patients and/or their relatives have been included as 'experts', for example, in a study on breast cancer services in Australia. ${ }^{28}$

There is also the potential for false consensus to be obtained, especially in situations where there is diversity of opinion on priorities. Studies showing agreement among different groups in the same study and with outside agencies have shown the method to have validity. ${ }^{28}$ The strengths and weaknesses of the nominal group technique and Delphi method are summarised in Box 3.

\section{Consensus?}

It is important to consider what is usually measured as 'consensus'. Some set out very explicit percentage cut-off points for consensus at the beginning of their study, 6,29 some do not ${ }^{30}$ and others use an arbitrary cut-off simply to limit the number of items considered. ${ }^{31}$ The requirement for consensus has been set as high as at $70 \%$ agreement for items ${ }^{32}$ but McKenna et al. reported a much lower $51 \%$ in an earlier paper. ${ }^{33}$

It is advisable to agree beforehand what will happen if no consensus can be reached, namely which treatment(s) will be recommended, if any, and which guideline will be recommended. For example, the above-mentioned nominal group technique addressing the UK Selected Practice Recommendations for Contraceptive Use agreed beforehand that "if no consensus was achieved in favour of any panellist's suggested alternative wording on a given topic, then the WHO Recommendation would be adopted 'by default' (unless there was consensus specifically against the WHO Recommendation)". 6

Sometimes of course consensus might not exist, or might not even be needed. There are many examples from everyday practice where different clinical practices exist in parallel, used by different professionals in the same field, each with its own proponents (e.g. the question whether or not one should clean the cord of a newborn baby with water or not at all). Lack of evidence either way means there is little common ground for consensus.

\section{Conclusions}

Both techniques can be useful in situations where little evidence exists but where, nevertheless, decisions about service provision need to be made. Similarly, they can be used to synthesise diverse evidence. The nominal group technique is also used to rank priorities and reach consensus but requires a physical meeting of participants and as such is open to group processes that do not affect the Delphi method. The inherent flexibility, as participants can moderate and/or change their opinion throughout the process of both methods, is a great advantage over more fixed methods such as one-off questionnaire studies. But one has to remember that the research can be affected by the selection of the panel members, response rates and way of dealing with minority responses. The literature suggests that it may be necessary to spend a little more and invest in an initial explanation of purpose and expected time commitment so as to increase the chances of participation. This in turn will increase the validity and generalisability of a study and fulfil the acceptability to participants. As with all methods, the more information provided by the researchers the better the reader is able to assess the quality of outcomes. For example, being informed of the response rate among experts to the invitation to participate; the proportion of experts who change their views through the Delphi method or nominal group technique; and the size and strength of minority views, would all help in the appraisal of the research.

\section{Statements on funding and competing interests \\ Funding. None identified.}

Competing interests. None identified.

References

1 Raine R, Sanderson C, Hutchings A, Carter S, Larkin K, Black N. An experimental study of determinants of group judgments in clinical guideline development. Lancet 2004; 364: 429-437.

2 Glasier A, Brechin S, Raine R, Penney G. A consensus process to adapt the World Health Organization selected practice recommendations for UK use. Contraception 2003; 68: 327-333.

3 Wang CC, Wang Y, Zhang K, Fang J, Liu W, Luo S, et al.. Reproductive health indicators for China's rural areas. Soc Sci Med 2003; 57: 217-225.

4 Zeitlin J, Wildman K, Breart G, Alexander S, Barros H, Blondel B, et al. Selecting an indicator set for monitoring and evaluating perinatal health in Europe: criteria, methods and results from the PERISTAT project. Eur J Obstet Gynecol Reprod Biol 2003; 111: S5-S14.

5 Powell C. The Delphi technique: myths and realities. J Adv Nurs 2003; 41: 376-382.

6 Faculty of Family Planning and Reproductive Health Care. A guide to using the UK Selected Practice Recommendations for Contraceptive Use. http://www.ffprhc.org.uk/admin/uploads/Final\%20WHO\% 20SPR\%20UK\%20version\%20intro.pdf [Accessed 15 August 2006].

7 Ryan M, Scott DA, Reeves C, Bate A, van Teijlingen ER, Russell 


\section{QUALITATIVE RESEARCH}

EM, et al. Eliciting public preferences for healthcare: a systematic review of techniques. Health Technol Assess 2001; 5: 1-186. http://www.hta.nhsweb.nhs.uk/fullmono/mon505.pdf [Accessed 15 August 2006].

8 Bowling A. Research Methods in Health: Investigating Health and Health Services. Buckingham, UK: Open University Press, 1997.

9 Scotland GS, Bullough CHW. What do doctors think their caseload should be to maintain their skills for delivery care? Int J Gynecol Obstet 2004; 87: 301-307.

10 Green B, Jones M, Hughes D, Williams A. Applying the Delphi technique in a study of GPs' information requirements. Health Soc Care Community 1999; 7: 198-205.

11 Keeney S, Hasson F, McKenna HP. A critical review of the Delphi technique as a research methodology for nursing. Int J Nurs Stud 2001; 38: 195-200.

12 Ferri CP, Prince M, Brayne C, Brodaty H, Fratiglioi L, Ganguli M, et al. Global prevalence of dementia: a Delphi consensus study. Lancet 2005; 366: 2112-2117.

13 Marsden J, Dolan B, Holt L. Nurse practitioner practice and deployment: electronic mail Delphi study. J Adv Nurs 2003; 43: 595-605.

14 Charlton JRH, Patrick DL, Matthews G, West PA. Spending priorities in Kent: a Delphi study. J Epidemiol Community Health 1981; 35: 288-292.

15 Murphy E, Dingwall R,Greatbatch D, Parker S, Watson P. Qualitative research methods in health technology assessment: a review of the literature Health Technol Assess 1998; 2: iii-ix, 1-274. http://www.hta.nhsweb.nhs.uk/fullmono/mon216.pdf [Accessed 15 August 2006]

16 Hardy DJ, O'Brien AP, Gaskin CJ, O’Brien AJ, Morrison-Ngatai E, Skews G, et al. Practical application of the Delphi technique in a bicultural mental health nursing study in New Zealand. $J$ Adv Nurs 2004; 46: 95-109.

17 Jones J, Hunter D. Qualitative research: consensus methods for medical and health services research. BMJ 1995; 311: 376-380.

18 Williams PL, Webb C. The Delphi technique: a methodological discussion. J Adv Nurs 1994; 19: 180-186.

19 Gallagher M, Bradshaw C, Nattress H. Policy priorities in diabetes care: a Delphi study. Qual Health Care 1996; 5: 3-8.
20 Oranga HM, Nordberg E. The Delphi panel method for generating health information. Health Policy Plan 1993; 8: 407.

21 Campbell SM, Braspenning J, Hutchinson A, Marshall M. Research methods used in developing and applying quality indicators in primary care. Qual Saf Health Care 2002; 11: 358-364.

22 Hasson F, Keeney S, McKenna H. Research guidelines for the Delphi survey technique. J Adv Nurs 2000; 32: 1008-1015.

23 Kapiriri L, Norheim OL. Whose priorities count? Comparison of community identified health problems and burden-of-diseaseassessed health priorities in a district in Uganda. Health Expect 2002; 5: $55-62$.

24 van Teijlingen ER, Pitchforth E. Focus group research in family planning and reproductive health care $J$ Fam Plann Reprod Health Care 2006; 32: 30-32.

25 McCourt C, Thomas BG. Evaluation of a problem-based curriculum in midwifery. Midwifery 2001; 17: 323-331.

26 Telford R, Boote JD, Cooper CL. What does it mean to involve consumers successfully in NHS research? A consensus study. Health Expect 2004; 7: 209-220.

27 Cantrill JA, Sibbald B, Buetow S. The Delphi and nominal techniques in health services research. Int J Pharm Pract 1996; 4: 67-74.

28 Redman S, Carrick S, Cockburn J, Hirst S. Consulting about priorities for the NHMRC National Breast Cancer Centre: how good is the nominal group technique. Aust N Z J Public Health 1997; 21: 250-256.

29 Stevenson L, Campbell NC, Kiehlmann PA. Providing cancer services to remote and rural areas: consensus study. $\mathrm{Br} J$ Cancer 2003; 89: 821-827.

30 Gibson JME. Using the Delphi technique to identify the content and context of nurses' continuing professional development needs. J Clin Nurs 1998; 7: 451-459.

31 Broomfield D, Humphris GM. Using the Delphi technique to identify the cancer education requirements of general practitioners. Med Educ 2001; 35: 928-937.

32 McKenna H, Hasson F, Smith M. A Delphi survey of midwives and midwifery students to identify non-midwifery duties. Midwifery 2002; 18: 314-322.

33 McKenna, HP. The Delphi technique: a worthwhile research approach for nursing? J Adv Nurs 1994; 19: 1211-1225.

\section{But is she positive?}

Your next patient is pregnant but doesn't want to be.

Where next? As a registered charity since 1968, bpas has offered affordable abortion care for women. We provide almost 50,000 abortions a year (including service agreements) and can offer all the professional help your patient needs.

bpas has a nationwide network of clinics and consultation centres. There are no long waits for appointments. We can offer a choice of times, clinics and procedures. All it takes to arrange an appointment is one call to the bpas Actionline on 08457304030.

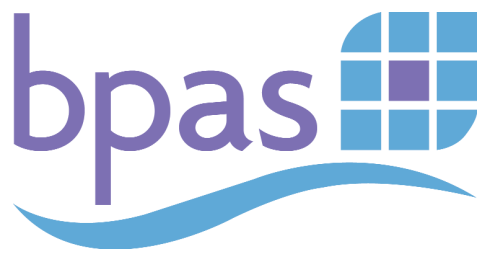

ACTIONLINE 08457304030 